\title{
UCRL-TR-221253
}

LAW RENCE LIVERMORE N A TIO NAL LABORATORY

Pressure Model for the Vacuum System for the Electron Gun and Injector for LCLS

Final Design Report

L. S. Tung, L. Eriksson

May 9, 2006 
This document was prepared as an account of work sponsored by an agency of the United States Government. Neither the United States Government nor the University of California nor any of their employees, makes any warranty, express or implied, or assumes any legal liability or responsibility for the accuracy, completeness, or usefulness of any information, apparatus, product, or process disclosed, or represents that its use would not infringe privately owned rights. Reference herein to any specific commercial product, process, or service by trade name, trademark, manufacturer, or otherwise, does not necessarily constitute or imply its endorsement, recommendation, or favoring by the United States Government or the University of California. The views and opinions of authors expressed herein do not necessarily state or reflect those of the United States Government or the University of California, and shall not be used for advertising or product endorsement purposes.

This work was performed under the auspices of the U.S. Department of Energy by University of California, Lawrence Livermore National Laboratory under Contract W-7405-Eng-48. 


\title{
LLNL/UCRL-XXXX
}

\section{Pressure model for the vacuum system for the electron gun and injector for LCLS}

\section{Final DesignReport}

\author{
Louann Tung \\ (NTED, LLNL) \\ and \\ Leif Eriksson \\ (LCLS, SLAC)
}

Submitted To: LCLS, SLAC

April 28, 2006

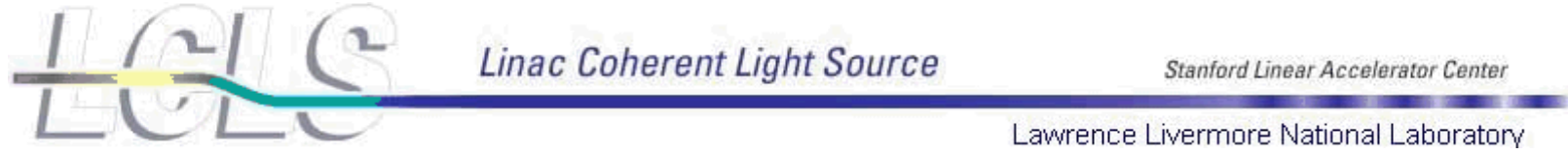




\section{Table of Contents}

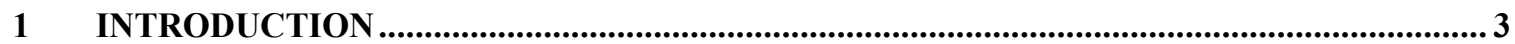

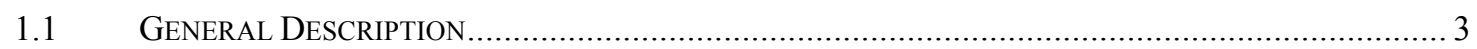

2 PERFORMANCE SPECIFICATIONS .............................................................................5

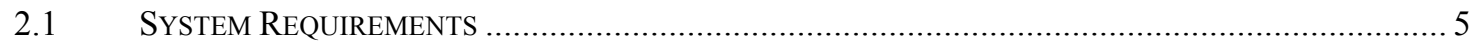

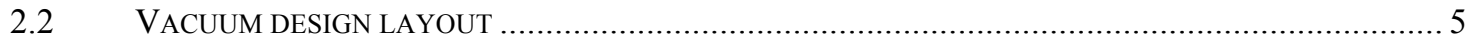

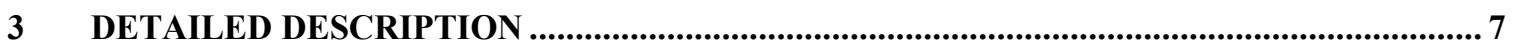

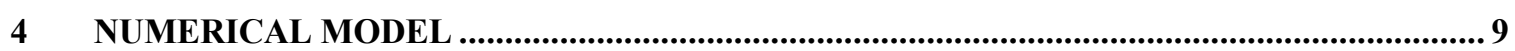

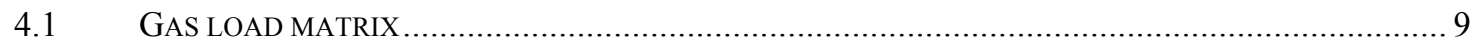

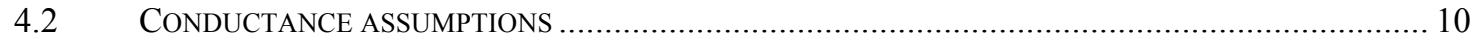

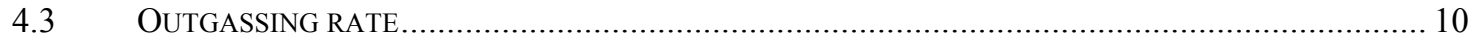

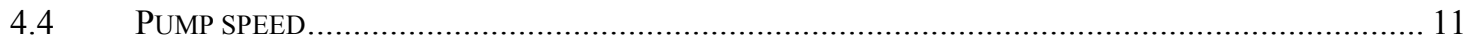

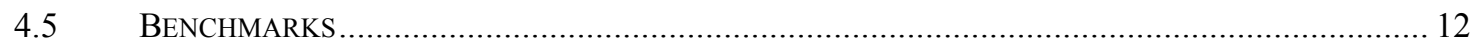

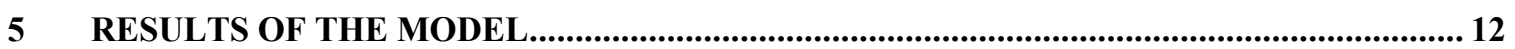

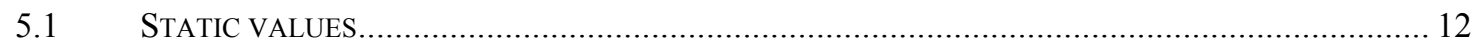

5.2 TIME-DEPENDENT RESULTS WITH CONSTANT OUTGASSING RATE ……................................... 17

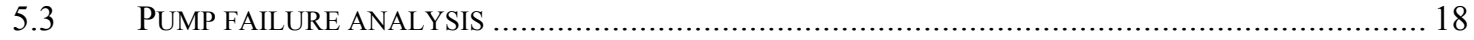

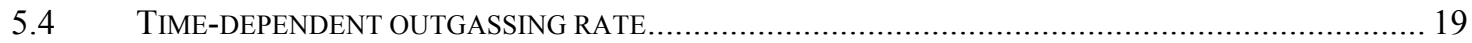

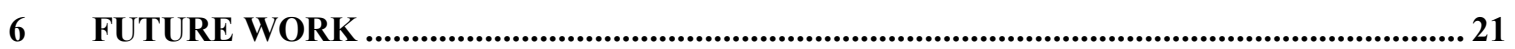

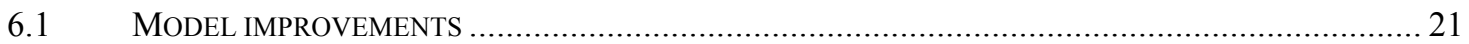

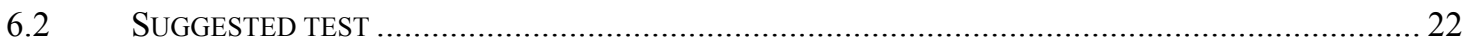

APPENDIX I : IL AND SASL COMPONENT LOCATIONS. ........................................................... 23

APPENDIX II : CODE TO CALCULATE Z VALUES OF COMPONENTS.................................. 24 


\section{Introduction}

The vacuum system of the injector for the Linac Coherent Light Source (LCLS) has been analyzed and configured by the Lawrence Livermore National Laboratory's New Technologies Engineering Division (NTED) as requested by the SLAC/LCLS program. The vacuum system layout and detailed analyses for the injector are presented in this final design report. The vacuum system was analyzed and optimized using a coupled gas load balance model of sub-volumes of the components to be evacuated.

\subsection{General Description}

The injector is comprised of the electron gun, a Gun Spectrometer Line a transport tube containing focusing magnets, diagnostics, and waveguides, an insertion line IL into the SLAC linac, and a straight ahead spectrometer line SASL that ends in a beam dump. The total evacuated length is 25.8 meters. A simple sketch of the vacuum system is shown in Fig. 1.1. There are nine vacuum pump locations and five valves. Light blue indicates the vacuum region that is modeled.

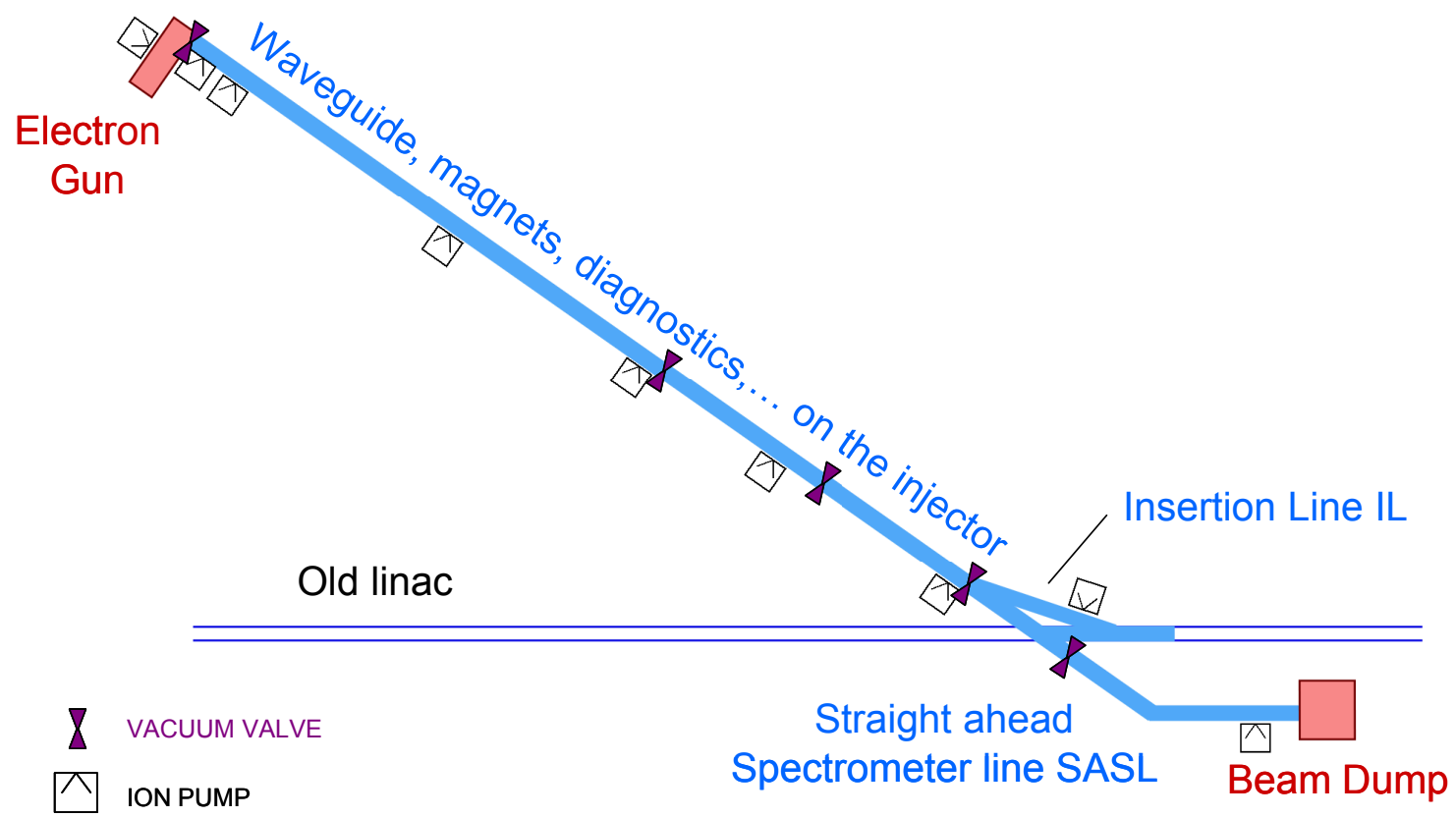

Fig. 1.1. Sketch of the injector vacuum system - the section modeled is shown in blue.

Three-dimensional renderings of the gun and the region where the injector inserts into the linac at the IL and at the SASL are provided in Fig. 1.2 and 1.3. 


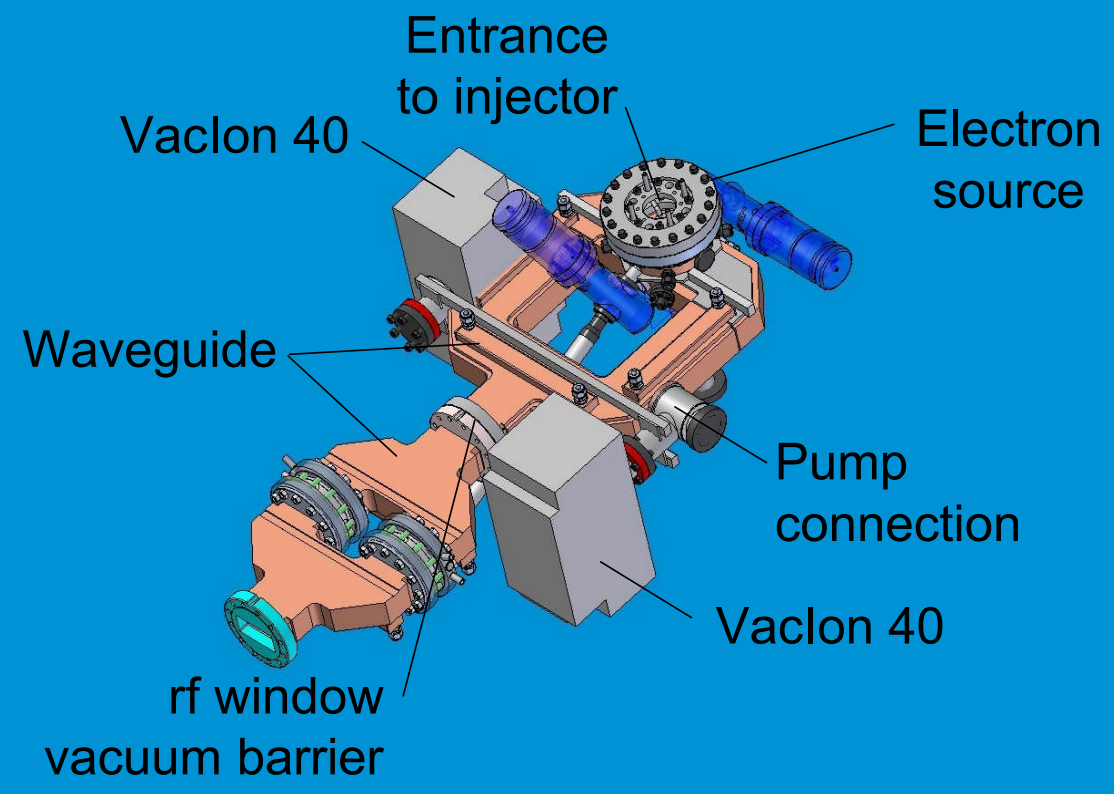

Fig. 1.2. Rendering of the electron gun

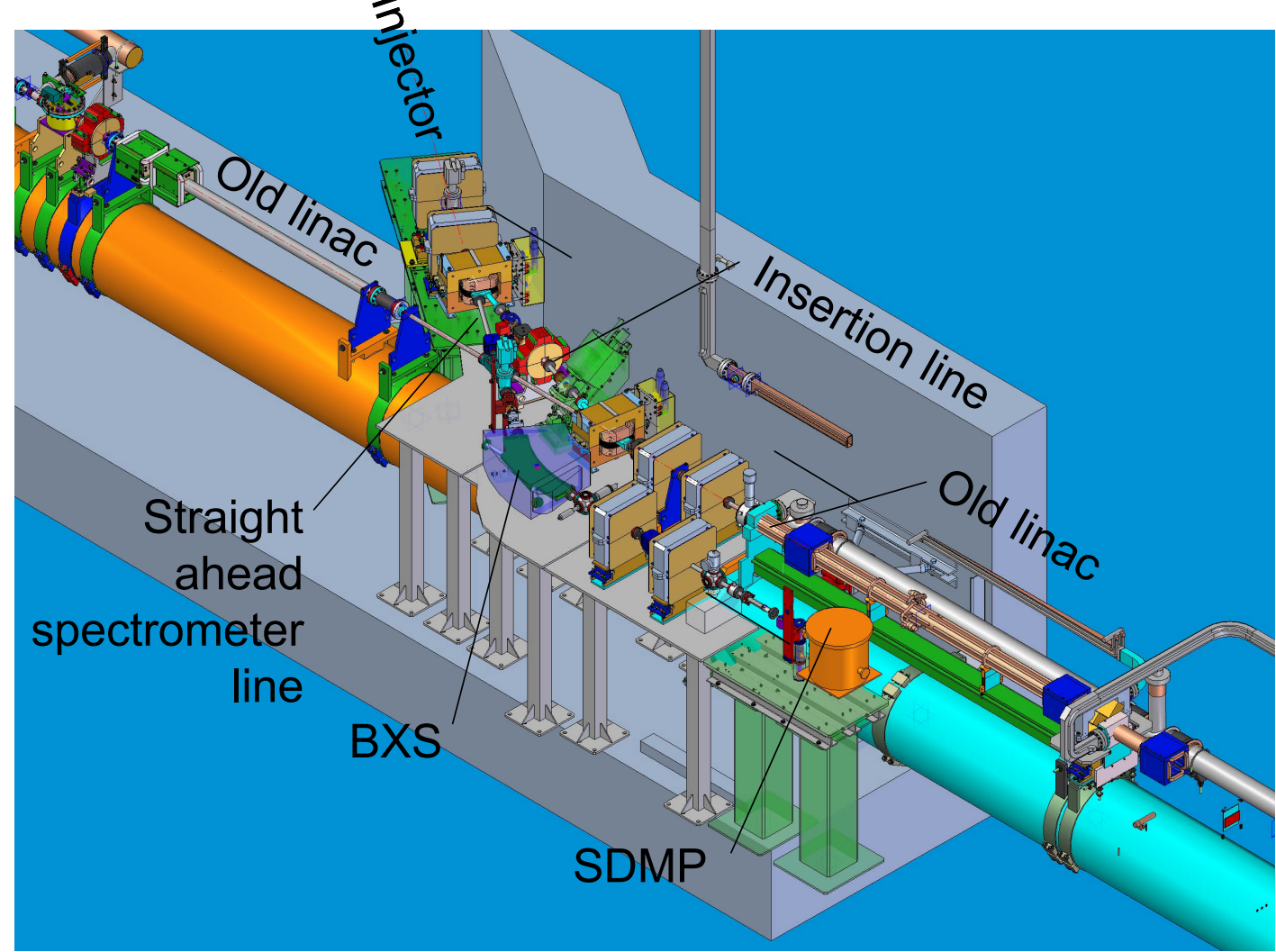

Fig. 1.3. Rendering of the injector near the SLAC linac 


\section{Performance Specifications}

\subsection{System Requirements}

The primary requirement for the injector vacuum system is to provide sufficient pumping to overcome the surface outgassing rate of the vacuum facing components. All surfaces are assumed to outgas at a rate of $2 \times 10^{-12}$ Torr-lit $/ \mathrm{sec} / \mathrm{cm}^{2}$. The leak rate of seals and valves were not included as they were considered relatively insignificant. The requirements and the final design values are summarized in Table 2.1. The calculated gun pressure did not meet the design values; however, LCLS vacuum staff felt that it was sufficiently within the pressure range to be acceptable. All pressures in the remaining injector tube were two orders of magnitude below the design value.

\begin{tabular}{|l|c|l|}
\hline \multicolumn{2}{|c|}{ PARAMETER } & \multicolumn{1}{c|}{ REQUIREMENTS / VALUE } \\
\hline Pumping to overcome system outgassing rate & $2 \times 10^{-12}$ Torr-lit/sec/ $/ \mathrm{cm}^{2}$ \\
\hline Gun pressure & Design & $3 \times 10^{-10}$ Torr \\
& Required & $1 \times 10^{-10}$ Torr \\
\hline Tube pressure & Design & $\begin{array}{l}7 \times 10^{-9} \text { Torr (max at the beam dump) } \\
2 \times 10^{-9} \text { Torr (average) }\end{array}$ \\
& Required & $<5 \times 10^{-7}$ Torr \\
\hline
\end{tabular}

Table 2.1. Injector System Requirements

\subsection{Vacuum design layout}

Turbo pump carts pump the system down to $10^{-6}$ Torr. Then carts are removed and Varian VacIon 40's and 20's noble diode ion pumps evacuate the system to the $10^{-9}$ Torr range and lower. The ion pumps maintain the system pressure for years of operation with minimal maintenance. The design pressure within the gun is in the $10^{-10}$ Torr range and the design pressure in the remaining system is $5 \times 10^{-7}$ Torr.

When the turbo carts pumps the system to $10^{-6}$ Torr, the outgassing rate of the internal surfaces is assumed to be a constant $2 \times 10^{-12}$ Torr. Described later in this report, we also conduct a study of time-dependent effects that would occur during commissioning. During the first pump-down, the outgassing rate will slowly decrease; hence, we also analyze the pressure response when the outgassing rate drops from $1 \times 10^{-}$ ${ }^{11}$ Torr-lit $/ \mathrm{s} / \mathrm{cm}^{2}$ to $2 \times 10^{-12}$ Torr-lit $/ \mathrm{s} / \mathrm{cm}^{2}$ over one day.

A sketch of the vacuum system and pump layout is shown in Fig. 2.1. There are 13 ion pumps in 9 locations. Varian VacIon ion pumps with a nominal speed of $40 \mathrm{lit} / \mathrm{s}$ (except two at P2 that are $20 \mathrm{lit} / \mathrm{s}$ ) are placed in the Gun and along the tube wherever space allows. Pumps in locations P1-P6 are connected with an arm (seen in Fig. 1.2) and "shower drain" (a 7 slit aperture to stop the rf propagation into the pump). Pumps in locations P7-P9 are connected only with a 1.5" Varian Tee. There are five valves labeled VV01through VV05 that can isolate the injector sections in case of leaks. (Valve VV05 in Fig. 4 is the same as VVSI in the LCLS drawings.) 
The gun entrance is referenced as $\mathrm{z}=0$. Distances from each component to the gun were calculated from the $x-y$ coordinates from the drawing \#SD380-020-06 (checked 11-18-05), element list, emailed drawing in App. I and emails from Leif Eriksson dated Dec. 2005 through Feb. 2006. Beyond the gun, the tube has an ID of 1.37 ' for $z<2.156$ $\mathrm{m}$ and 0.87 " for $\mathrm{z}>2.156 \mathrm{~m}$. There are 25.8 meters of injector tube analyzed in our gas load model.

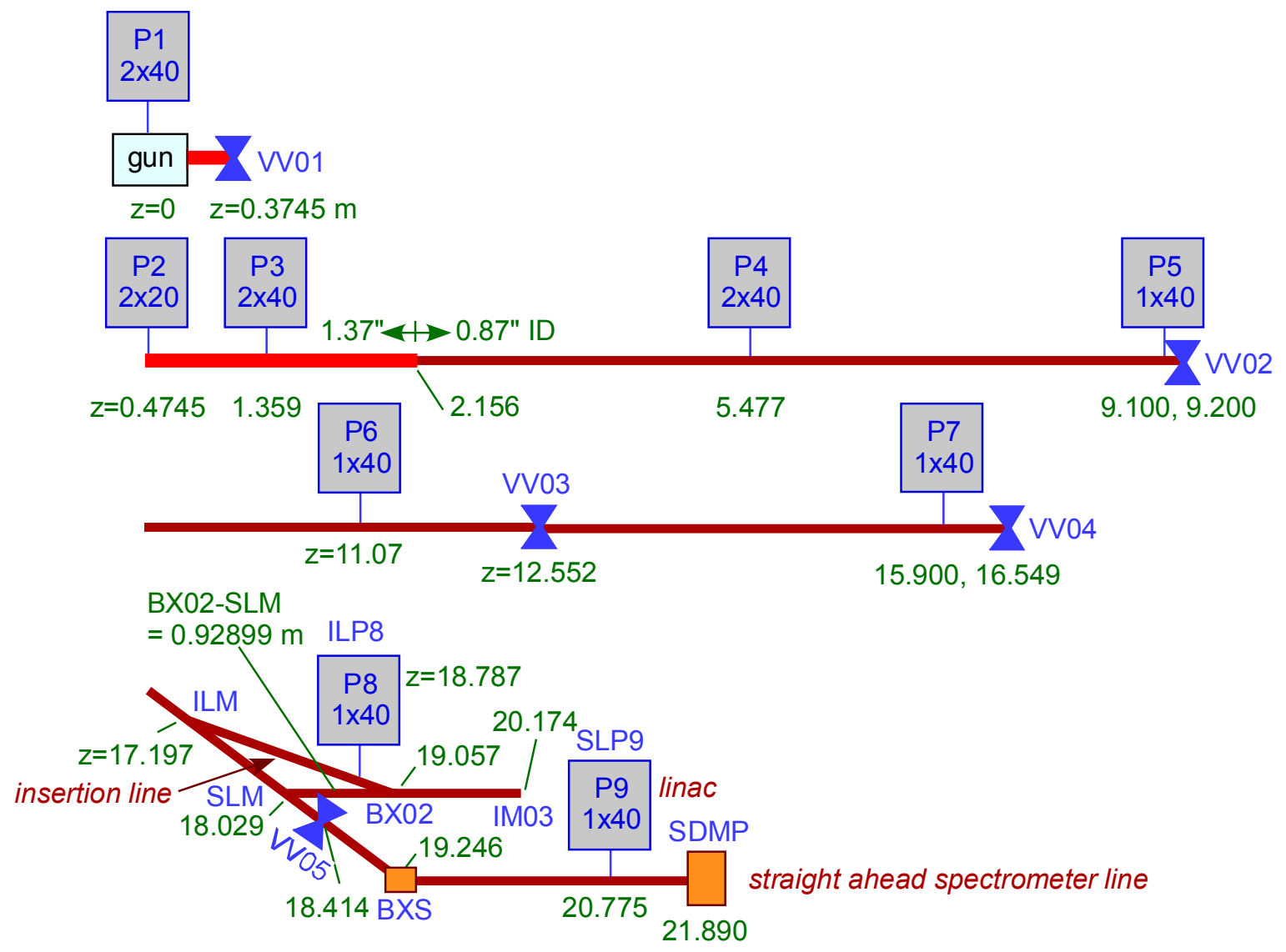

Fig. 2.1. Layout of the LCLS Injector vacuum system. 


\section{Detailed description}

Details of the gun are shown in Fig. 3.1. Each color represents one discrete element or sub-volume in the vacuum model. There are actually 4 sub-volumes but the problem can be reduced to three by symmetry. Node 1 includes the volumes and surface areas of the "Y" waveguide (in blue) and the two alumina rf windows. These windows also provide a vacuum seal between the Gun and the incoming RF wave guide. Node 2 (in yellow) includes the volumes and surface areas of the rectangular " $\mathrm{O}$ " of the waveguide and the two connections to the ion pumps. Node 3 (in purple) describes the small details within the electron gun. Node 3 connects to the remaining components of the injector. Also shown are the conductances between nodes (described in more detail later) where $\mathrm{Cwg}$, Ciris, Carm, and Csd refers to the conductance of the waveguide (1/4 of the perimeter), iris (opening to the gun), arm (pump to waveguide elbow), and shower drain, respectively.

The internal surface area and volume of the vacuum system was calculated for the tube section. The surface area and volumes of the remaining components was provided by SLAC. These values including the gun region components are summarized in Table 3.1.

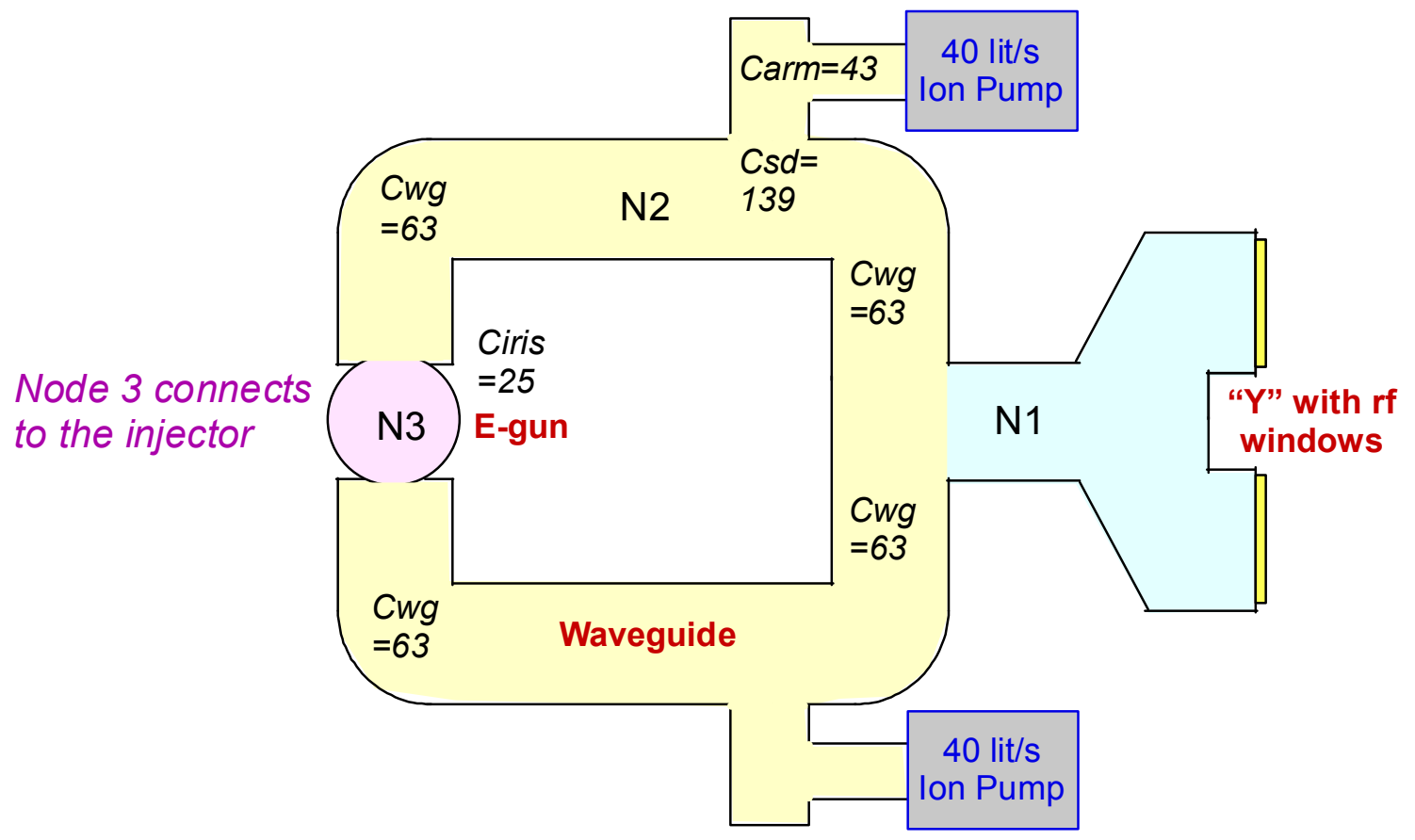

Fig. 3.1. Sketch of electron gun and waveguide section to show the breakdown of the geometry into 3 nodes to model in the gas load matrix. 


\section{GUN REGION}

GUN (cavity + back space)

Volume $=22.808+7.558 \mathrm{in}^{3}$

Area $=63.134+66.219 \mathrm{in}^{2}$

SQUARE WAVEGUIDE

Volume $=158.178 \mathrm{in}^{3}=2.592 \mathrm{lit}$

Area $=353.444 \mathrm{in}^{2}=2280 \mathrm{~cm}^{2}$

Width $=2.84$ in

Thickness $=1.34$ in

\section{Y WAVEGUIDE + RF WINDOWS}

Volume $=67.57 \mathrm{in}^{3}$

Area $\mathrm{Cu}=134.28$ in $^{2}$

Area SS $=4.55 \mathrm{in}^{2}$

Area two rf windows $=17.45 \mathrm{in}^{2}$

IRIS at gun entrance

Diameter $=0.65$ in

SHOWER DRAIN between waveguide and pump arms

7 slots each composed of 1 rectangle $(0.25$ " $\mathrm{x}(1.26-0.25)$ ") and

two half-circles (0.25" Dia.)

ARMS connecting waveguide to pumps

Dia Arm1 = 1.62" Length Arm1 = 3.71"

Dia Arm2 = 2.26" Length Arm2 = 2.85" (scaled from drawing pg 1)

\section{INJECTOR REGION}

INJECTOR DIAMETER

$\mathrm{ID}=1.37$ " for $\mathrm{z}<2.156 \mathrm{~m} \quad \mathrm{ID}=0.87$ " for $\mathrm{z}>2.156 \mathrm{~m}$

INJECTOR $x-y$ and SUML or $z$ coordinates are listed in App. II.

BXS on SASL (two tubes)

Volume $=2 \times 115 \mathrm{~cm}^{3} \quad$ Area $=2 \times 208 \mathrm{~cm}^{2}$

SDMP on SASL (beam dump)

Volume $=39,517 \mathrm{~cm}^{3} \quad$ Area $=2696 \mathrm{~cm}^{2}$

Table 3.1. Summary of dimensions provided by SLAC that are used in the model 


\section{$4 \quad$ Numerical model}

\subsection{Gas load matrix}

Our numerical model of the vacuum system analyzes the gas load balance using a discrete description using nodes or sub-volumes. These nodes are connected to each other through series conductances. For example, the gun region of Fig. 3.1 can be converted to a nodal model as shown below in Fig. 4.1. Here the conductance between nodes 1 and 2 is $C_{1,2}=2 C_{w g} ; C_{2, p}=2 /\left(C_{a r m}{ }^{-1}+C_{s d}{ }^{-1}\right)$; and $C_{2,3}=2 /\left(C_{i r i s}{ }^{-1}+C_{w g}{ }^{-1}\right)$. Note that the factor of 2 is because the opposite side of the waveguide that includes the second pump is folded into the first side because of symmetry.

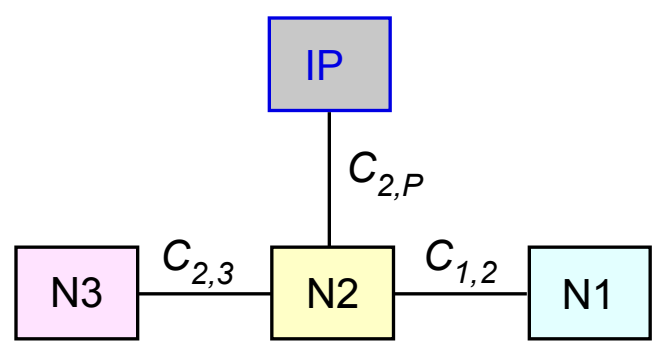

Fig. 4.1. Nodal relationships for the gun region used in the gas load matrix

Pressure history is studied by solving the coupled gas load equations between all the nodes. Mathematica ${ }^{*}$ is used to do the numerical modeling. The outgassing rate is assumed to be constant because the system has been pumped for a long time to reach a constant pressure of 10-6 Torr. (The results of time-depending outgassing rate is shown later.) This is the initial condition to solve the gas load matrix. The gas load equations, shown below, are solved simultaneously for all nodes for each timestep until a constant pressure is reached.

$\mathrm{V}_{\mathrm{i}} \mathrm{dp}_{\mathrm{i}} / \mathrm{dt}=\Sigma \mathrm{Q}_{\mathrm{i} \text { in }}-\Sigma \mathrm{Q}_{\mathrm{i} \text { out }}$

where $\mathrm{i}$ is the index for the $\mathrm{i}$-th volume,

$\mathrm{V}$ is the volume (lit);

$\mathrm{dp}_{\mathrm{i}} / \mathrm{dt}$ is the rate of change in pressure (Torr/sec);

$\Sigma \mathrm{Q}_{\mathrm{i}}$ in is the sum of surface outgassing or leakage into $\mathrm{V}_{\mathrm{i}}$ (Torr-lit/sec);

(surface outgassing is a function of time; O-ring leakage is constant)

and $\Sigma \mathrm{Q}_{\mathrm{i} \text { out }}$ is sum of the gas throughput from $\mathrm{V}_{\mathrm{i}}$ into $\mathrm{V}_{\mathrm{j}}$,

where $\mathrm{Q}_{\mathrm{i} \text { out }}=\mathrm{C}_{\mathrm{i} \rightarrow \mathrm{j}}\left(\mathrm{p}_{\mathrm{i}}-\mathrm{p}_{\mathrm{j}}\right)$

and $\mathrm{C}_{\mathrm{i} \rightarrow \mathrm{j}}$ is the conductance (lit/sec);

and/or $\Sigma \mathrm{Q}_{\mathrm{i} \text { out }}$ is sum of the gas throughput out of $\mathrm{V}_{\mathrm{I}}$,

\footnotetext{
${ }^{*}$ Mathematica 5.2 by Wolfram.
} 
where $\mathrm{Q}_{\mathrm{i} \text { out }}=\mathrm{S} \mathrm{p} \mathrm{p}_{\mathrm{i}}$,

where $\mathrm{S}$, the effective pump speed (lit/sec), is

$\mathrm{S}=\mathrm{S}_{\mathrm{p}}\left(\mathrm{p}_{\mathrm{i}}\right) \mathrm{C}_{\mathrm{p}} /\left(\mathrm{S}_{\mathrm{p}}\left(\mathrm{p}_{\mathrm{i}}\right)+\mathrm{C}_{\mathrm{p}}\right.$

where $\mathrm{C}_{\mathrm{p}}$ is the conductance between $V_{i}$ and the pump

and $\mathrm{S}_{\mathrm{p}}\left(\mathrm{p}_{\mathrm{i}}\right)$ is the pressure dependent pump speed.

\subsection{Conductance assumptions}

\section{Shape}

Long tube

\section{Conductance (lit/sec)}

$$
12.1\left(\mathrm{D}^{3} / \mathrm{L}\right)\left(15 \mathrm{~L} / \mathrm{D}+12(\mathrm{~L} / \mathrm{D})^{2}+\left(20+38 \mathrm{~L} / \mathrm{D}+12(\mathrm{~L} / \mathrm{D})^{2}\right)^{\dagger}\right.
$$

Two short tubes with $90^{\circ}$ bend

$$
\begin{array}{ll} 
& 12.1\left(\mathrm{D}^{3} /(\mathrm{L} 1+\mathrm{L} 2+1.33(90 / 180) \mathrm{D})^{\ddagger}\right. \\
\text { Rectangular duct } & 30.9 \mathrm{a}^{2} \mathrm{~b}^{2} \mathrm{~K} /((\mathrm{a}+\mathrm{b}) \mathrm{L}+2.66 \mathrm{ab})^{\S}
\end{array}
$$

where $\mathrm{L}=$ tube or duct length $(\mathrm{cm}), \mathrm{D}=\operatorname{diameter}(\mathrm{cm}), \mathrm{a}=$ long side $(\mathrm{cm}), \mathrm{b}=$ short side $(\mathrm{cm}), \mathrm{A}=$ area $\left(\mathrm{cm}^{2}\right)$ and $\mathrm{K}$ depends on $\mathrm{b} / \mathrm{a}^{* *}$.

The waveguide conductances were based on the formula for a rectangular duct. The length used in the conductance calculation should be the distance between the iris and the pump entrance to the waveguide at the "shower drain". Since this value is not obvious from the drawings, the value was calculated by using $1 / 4$ of the value of the average internal length as based on the total waveguide volume divided by the perimeter $=2$ (width + thickness).

The conductance of the shower drain uses the conductance for a rectangular duct rather than an aperture. This shower drain has a thickness of 0.3 " which is larger than a slot width of 0.25 " so the aperture formula is not valid.

The conductance of the pump arms uses the formula for two short tubes with a $90^{\circ}$ bend. The arm with the smaller diameter was used in the formula. Although one tube intersected the second tube midway, the full length of the $2^{\text {nd }}$ tube was used.

\subsection{Outgassing rate}

The outgassing rate used for all the metal surfaces is $2 \times 10^{-12}$ Torr-lit $/ \mathrm{sec} / \mathrm{cm}^{2}$. However to account for unknown small areas buried along the tube, we use $2.4 \times 10^{-12}$ Torr-lit $/ \mathrm{sec} / \mathrm{cm}^{2}$ for all areas outside of the gun $(i \geq 4)$. This low rate assumes that the system has been pumped for a long time (days) using turbo pumps. It also assumes that the ion pumps are turned on when the outgassing rate has reached this final constant value.

\footnotetext{
${ }^{\dagger}$ Roth, A., 1998, Vacuum Technology, (North Holland, Amsterdam) 87.

Ibid, 91 .

${ }^{\S}$ Ibid, 87.

** Ibid, 85 .
} 


\subsection{Pump speed}

The VacIon40 Noble Diode pumps have a nominal speed of 40 lit/sec; however, the actual speed depends on pressure as shown in Fig. 4.2. This graph was scanned from the Varian catalog and fit to a formula that is used in the Mathematica model. The pressures near the pumps resulted in an actual pumping speed that varied between 28 and $31 \mathrm{lit} / \mathrm{sec}$.

As observed in previous linacs, the gas composition in the vacuum system is mostly hydrogen; $;^{\dagger \dagger}$ however, we assume that dry nitrogen is being pumped. The assumption will predict a higher pressure for two reasons. First, the noble ion diode pumps remove hydrogen at a rate that is roughly 1.7 times that of nitrogen. Second, the conductance values are based on the above equations that assume the gas is air (dry nitrogen) at $20^{\circ} \mathrm{C}$. Conductances for pure hydrogen would be 3.8 times higher since conductance scales with the square root of the molecular weight. Since the exact composition is unknown and will vary with time, choosing air (dry nitrogen) provides the most conservative pressure calculation.

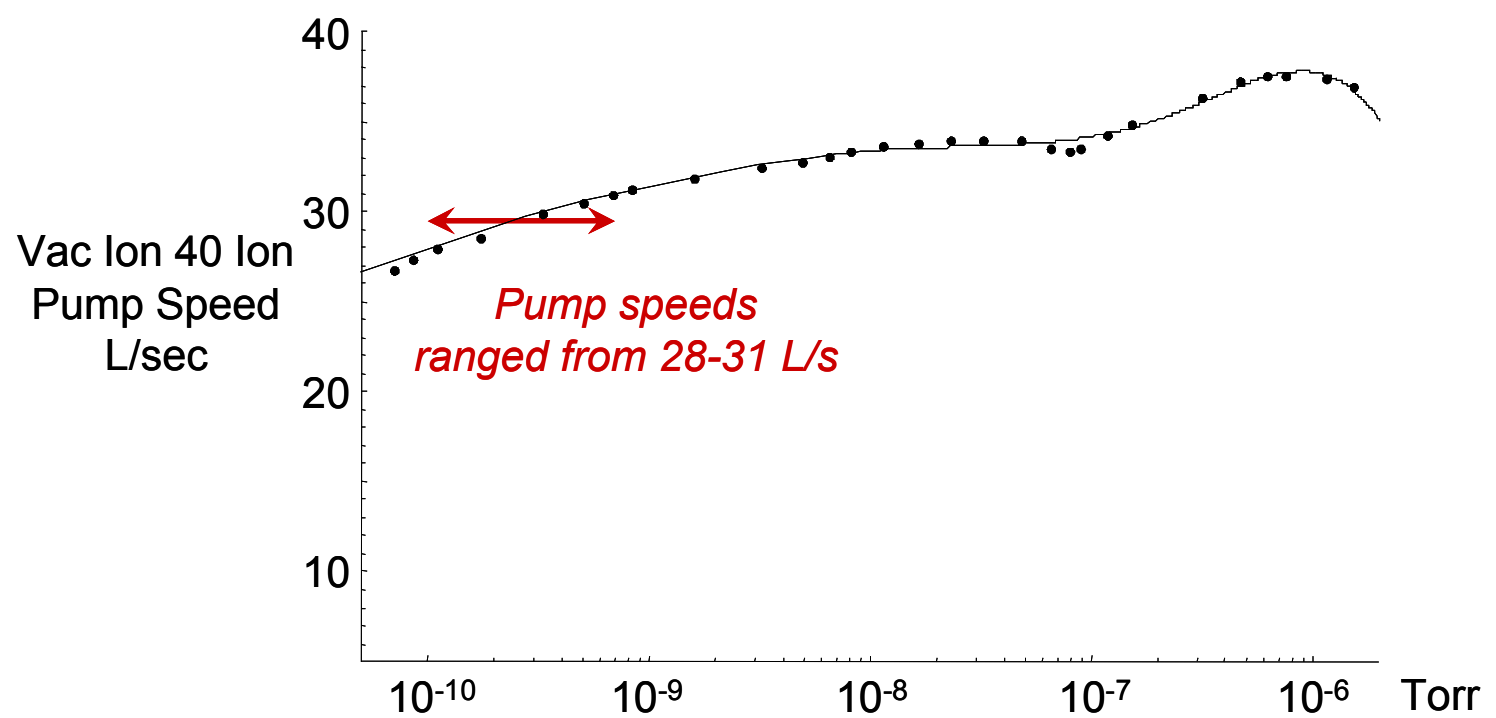

Fig. 4.2. Pressure dependence of pump speed for the VacIon40 Noble Diode ion pump. Dots represent the catalog data. The line represents the numerical fit which is $S(p)=33.7219+120.379 \operatorname{Sin}(0.1667 \log (p))^{11}-42.1059 \operatorname{Sin}(0.1682 \log (p))^{5}-$ 2.3765 $\operatorname{Sin}\left(0.2196 \log (p){ }^{9}\right.$, which is only good for $9 \times 10^{-11}$ to $2 \times 10^{-6}$ Torr.

\footnotetext{
${ }^{\dagger \dagger}$ Liu, Chan and John Noonan, Argonne National Lab/Advanced Photon Source/Technical Bulletin 1995, "Advanced Photon Source Accelerator Ultrahigh Vacuum Guide", 18.
} 


\subsection{Benchmarks}

The design presented in this report is based on the experience with accelerator projects such as APT/RFQ, APT/LEDA/DTL-CCL ${ }^{\dagger \dagger}$, SNS/DTL-CCL, DARHT II, and SLAC B-Factory. Past applications were models of accelerator cavities connected with apertures. The technique of using this method on long narrow tubes is novel for this design and that of the LCLS/XTOD tunnel thus a benchmark was conducted.

A simple test was run that described a single pump at the end of long tube. The theoretical prediction is that

$$
\mathrm{p}(\mathrm{x})=\mathrm{q} B\left(\mathrm{~L} / \mathrm{S}+\mathrm{x} / \mathrm{C}-\mathrm{x}^{2} /(2 \mathrm{CL})\right)^{\dagger}
$$

where $q=$ outgassing rate (Torr-lit $\left./ \mathrm{sec} / \mathrm{cm}^{2}\right), B=$ perimeter $(\mathrm{cm}), S=$ pump speed (lit/sec), $L=$ length $(\mathrm{cm})$ between the pump and end, and $x$ is the distance from the pump.

The trick was how to divide up a long tube into discrete elements that not only outgas but also restrict the flow of gas. The tube is divided into $N$ discrete sections or sub-volumes. The conductance of each sub-volume is just the total conductance of the tube of length $L$ times the number of sub-volumes. (Applying the conductance formula to individual sub-volumes gave an answer that did not agree with theory.) As $N$ was increased then the solution using the discrete model converged with theory. We found that if the sub-volume length was at least the size of the tube diameter (i.e. SVF $>1$ ), then the model was accurate.

In the injector model, the subvolume length is equal to the twice the smallest tube diameter which has an ID $=0.87$ '. Thus $\mathrm{SVF}=2$ and $N=586$. For this case, the run time was $23 \mathrm{sec}$ on a $1.6 \mathrm{GHz}$ PC. When $\mathrm{SVF}=0.2$ then $N=5839$ then the run time was 3.4 hours. The system average pressure for both cases was within $0.3 \%$. Thus we have confidence in our discrete model using $\mathrm{SVF}=2$.

\section{$5 \quad$ Results of the model}

\subsection{Static values}

The data from Table 3.1 is transformed into nodal information and summarized in Table 5.1. The total outgassing load is $6.63 \times 10^{-8}$ Torr-lit/sec. Total nominal pumping speed is $480 \mathrm{lit} / \mathrm{sec}$; however, the total effective pumping speed of the 13 ion pumps is $185.5 \mathrm{lit} / \mathrm{sec}$. This total includes the local pressure dependence of pumping speed and the pump connections. Thus using the simple prediction of $P=Q / S$, then the average pressure is expected to be $3.6 \times 10^{-10}$ Torr which assumes no conductance loss in the tube.

We chose a subvolume width that is twice the minimum tube diameter. Thus the subvolume width is 2 x 0.87 ". This subvolume factor SVF of 2 was optimized by comparing the accuracy of the final pressure with runtimes (discussed later). With SVF = 2, the layout of indices is shown in Fig. 5.1. With 3 nodes in the gun section and 25.8 meters of tube and SVF $=2$, then the number of nodes is 586. The first 3 indices are with the gun section. Then $\mathrm{i}=4$ is the first node in the tube. The indices then follow the tube

\footnotetext{
\# APT LEDA CCDTL Phase 3A PDR Appendix 7A, LLNL/APT 99003.

$\$$ Roth, A., 1998, Vacuum Technology, (North Holland, Amsterdam) 133.
} 
through ILM and the insertion line and end at the linac at IM03. The next index starts on the SASL next to the ILM and indices increase along the SASL until the beam dump at SDMP. Finally the last section along the linac is picked up starting with SLM and ending at BX02.

The final plot of the pressure profile is shown in Fig. 5.2. Note in Fig. 5.1, there are nodes at 3 different locations that are connected: where the IL and SASL split at ILM, where the IL meets the linac at BX02, and where the SASL meets the linac at SLM. Thus these three locations have 2 non-sequential nodes that have nearly the same pressures. So one can see on the plot that at ILM that pressures are the same at $\mathrm{i}=390$ and 459 ; at BX03 pressures are the same at $i=433$ and 586; and at SLM pressures are the same at $i=477$ and 565.

The gun pressure $(i=3)$ is $3.3 \times 10^{-10}$ Torr. The minimum pressures are found at the indices closest to the pumps at the nine locations. (See Section 6 for a discussion on pump throat pressures.) The local maxima pressures are in between the pumps with the highest pressure at the beam dump at $7.0 \times 10^{-9}$ Torr. The system average pressure is 2.2 $\mathrm{x} 10^{-9}$ Torr. This calculated value is 6 times higher than the simple estimate of $3.6 \times 10^{-10}$ Torr because of the small conductance of the tube. Note that where the tube ends at IM03 and at SLM there is no accounting for pumping beyond this system. Thus the ends are assumed to be sealed. This assumption will give a slightly higher pressure than when this system is connected to the rest of the linac that will provide some additional pumping. 


\section{GUN REGION}

\begin{tabular}{|c|c|c|}
\hline NODES & Vol, lit & Surface area, $\mathrm{cm}^{2}$ \\
\hline $\mathrm{N} 1, \mathrm{Y}+\mathrm{rf}$ & 2 arms & 1.107 \\
\hline $\mathrm{N} 2$, waveguide +2 arms & 2.593 & 2942 \\
\hline N3, Gun & 0.498 & 835 \\
\hline Total & 4.198 & 5446 \\
\hline
\end{tabular}

CONDUCTANCE between nodes

Ciris $=24.8 \mathrm{lit} / \mathrm{sec}$

$\mathrm{Cwg}=26.4 \mathrm{lit} / \mathrm{sec}$ (waveguide quarter length)

Csd $=139.1 \mathrm{lit} / \mathrm{sec}$ (shower drain with 7 slots)

Carm $=43.5$ lit $/ \mathrm{sec}$

$\mathrm{C}_{2,3} \quad=2\left(\mathrm{Ciris}^{-1}+\mathrm{Cwg}^{-1}\right)^{-1} \quad=33.1 \mathrm{lit} / \mathrm{sec}$

$\mathrm{C}_{2, \mathrm{P}} \quad=2\left(\mathrm{Carm}^{-1}+\mathrm{Csd}^{-1}\right)^{-1} \quad=66.23$

$\begin{array}{lll}\mathrm{C}_{1,2} & =2 \mathrm{Cwg} & =125.1\end{array}$

\section{INJECTOR REGION}

\section{NODES}

$\mathrm{N} 1, \mathrm{Y}+\mathrm{rf}$ windows +2 arms

$\mathrm{N} 2$, waveguide +2 arms

N3, Gun
Vol, lit Surface area, $\mathbf{c m}^{2}$

$1.107 \quad 1008$

$3.217 \quad 2785$

$0.498 \quad 835$

CONDUCTANCE between nodes

For $\mathrm{z}<2.156 \mathrm{~m}=111.7 \mathrm{lit} / \mathrm{sec}$

For $\mathrm{z}>2.156 \mathrm{~m}=29.40 \mathrm{lit} / \mathrm{sec}$

CONDUCTANCE to pumps \& EFFECTIVE PUMPING SPEED if $S=30 \mathrm{lit} / \mathrm{sec}$

For pumps 1-6: $\quad$ Carm $/ \mathrm{sd}=33.1 \mathrm{lit} / \mathrm{sec} \quad$ Seff $=15.7 \mathrm{lit} / \mathrm{sec}$

For pumps 7-9: $\quad$ Ctee $=44.5 \mathrm{lit} / \mathrm{sec}($ Varian Tee $) \quad$ Seff $=17.9 \mathrm{lit} / \mathrm{sec}$

\section{LUMPED VALUES}

$\begin{array}{llll}\text { NODES } & \text { Vol, lit } & \text { Surface area, } \mathbf{c m}^{2} & \begin{array}{l}\text { Outgassing rate, Torr-lit/sec } \\ 6.63 \times 10^{-8}\end{array} \\ \text { All } & 57.81 & 28,401 & 6.63 \times 1\end{array}$

Table 5.1. Summary of calculated parameters used in the gas load matrix 


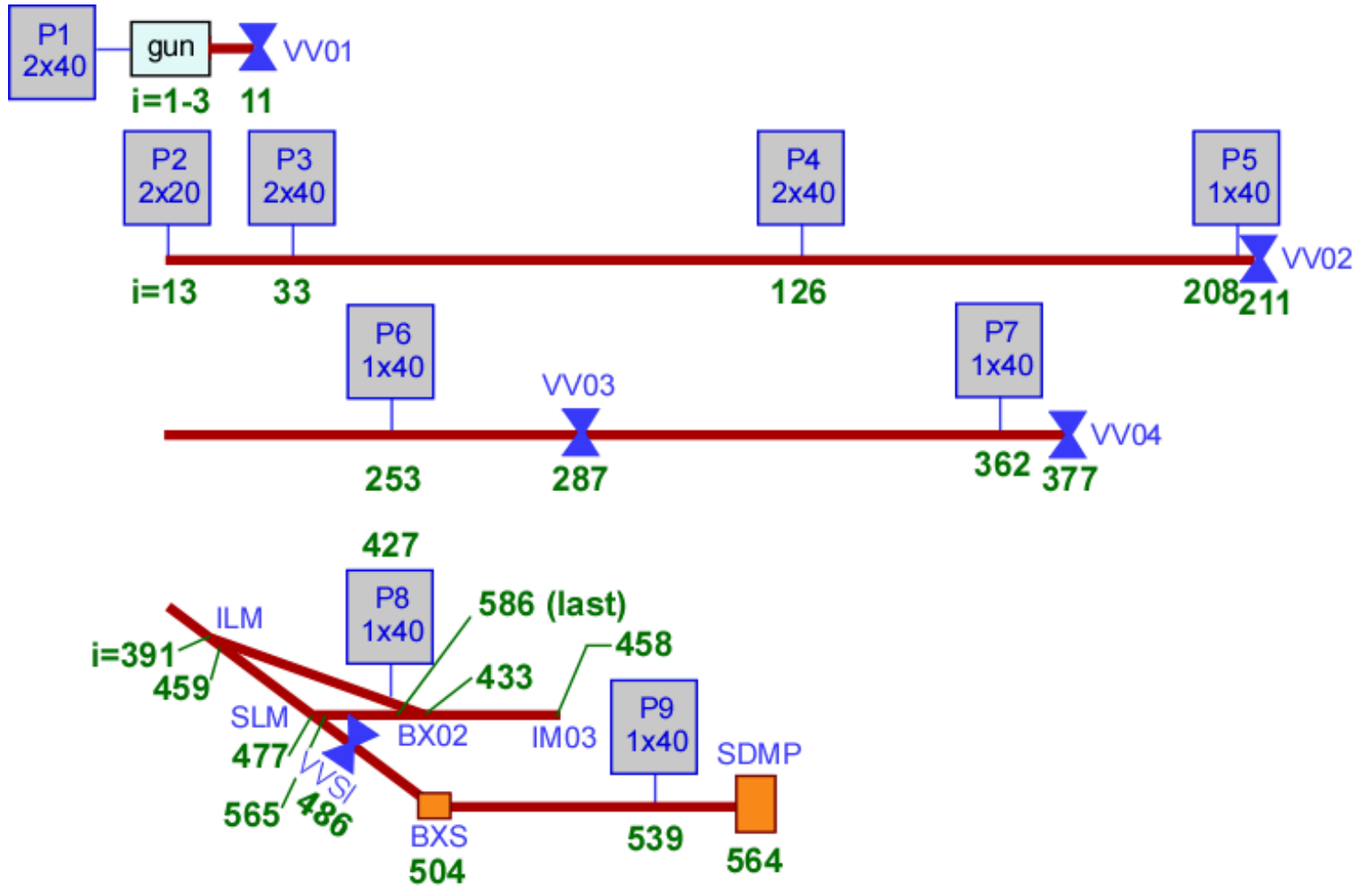

Fig. 5.1. Layout of indices for $N=586$ generated with $S V F=2$ 


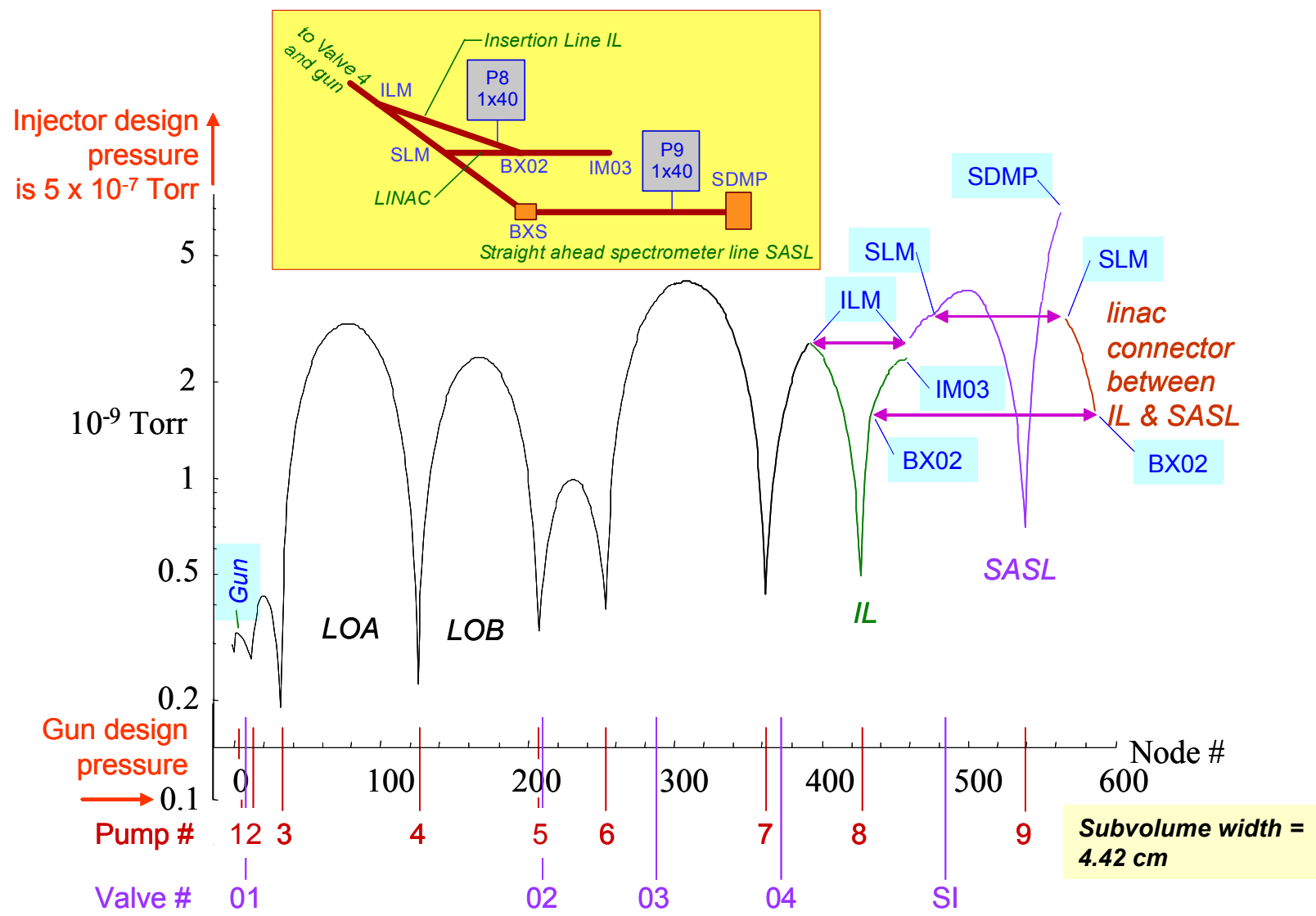

Fig. 5.2. Pressure profile of the entire injector with an outgassing rate of $2 \times 10^{-12}$ Torr$\mathrm{lit} / \mathrm{sec} / \mathrm{cm}^{2}$. Inset shows the details of the injector at the IL and SASL. The gun pressure $(i=3)$ is $3.3 \times 10^{-10}$ Torr. System average pressure is $2.2 \times 10^{-9}$ Torr. Maximum pressure (at SDMP) is $7.0 \times 10^{-9}$ Torr. 


\subsection{Time-dependent results with constant outgassing rate}

For the above results, the outgassing rate is set at $2 \times 10^{-12}$ Torr-lit $/ \mathrm{sec} / \mathrm{cm}^{2}$. Thus the only time-dependent behavior is just the time to pump out the gas in the enclosed volumes. Initially the system pressure is $1 \times 10^{-6}$ Torr. Plots of the time-history of pressure at the gun and at the beam dump are shown in Fig. 5.3 and Fig. 5.4. The gun pressure equilibrates in 4 seconds and the beam dump by 400 seconds. The beam dump pressure takes considerably longer to equilibrate since its volume is larger and the nearest pump is 1.1 meters away.

\section{Early Gun pressure, Torr}

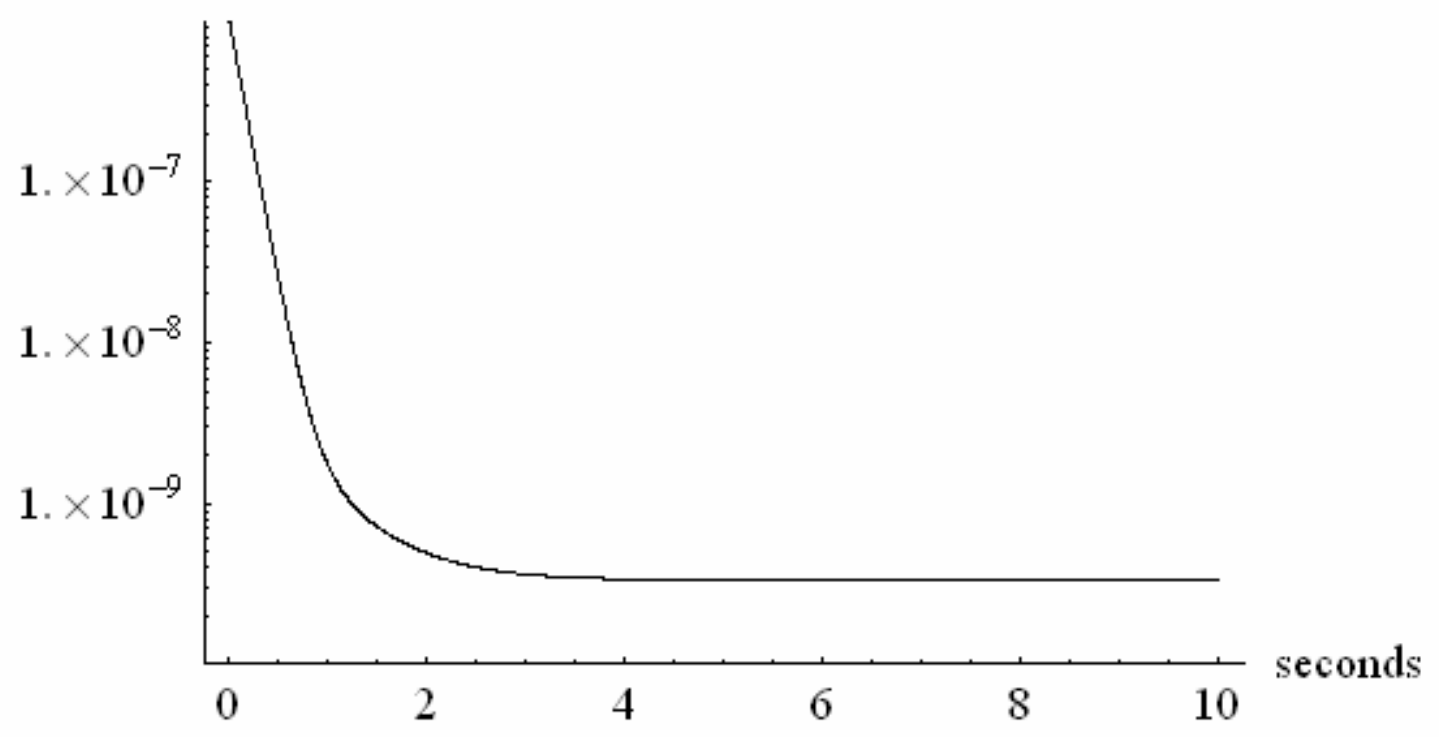

Fig. 5.3. Pressure history at the gun $(i=2)$. Final pressure $=3.3 \times 10^{-10}$ Torr. 
Early SDMP pressure, Torr

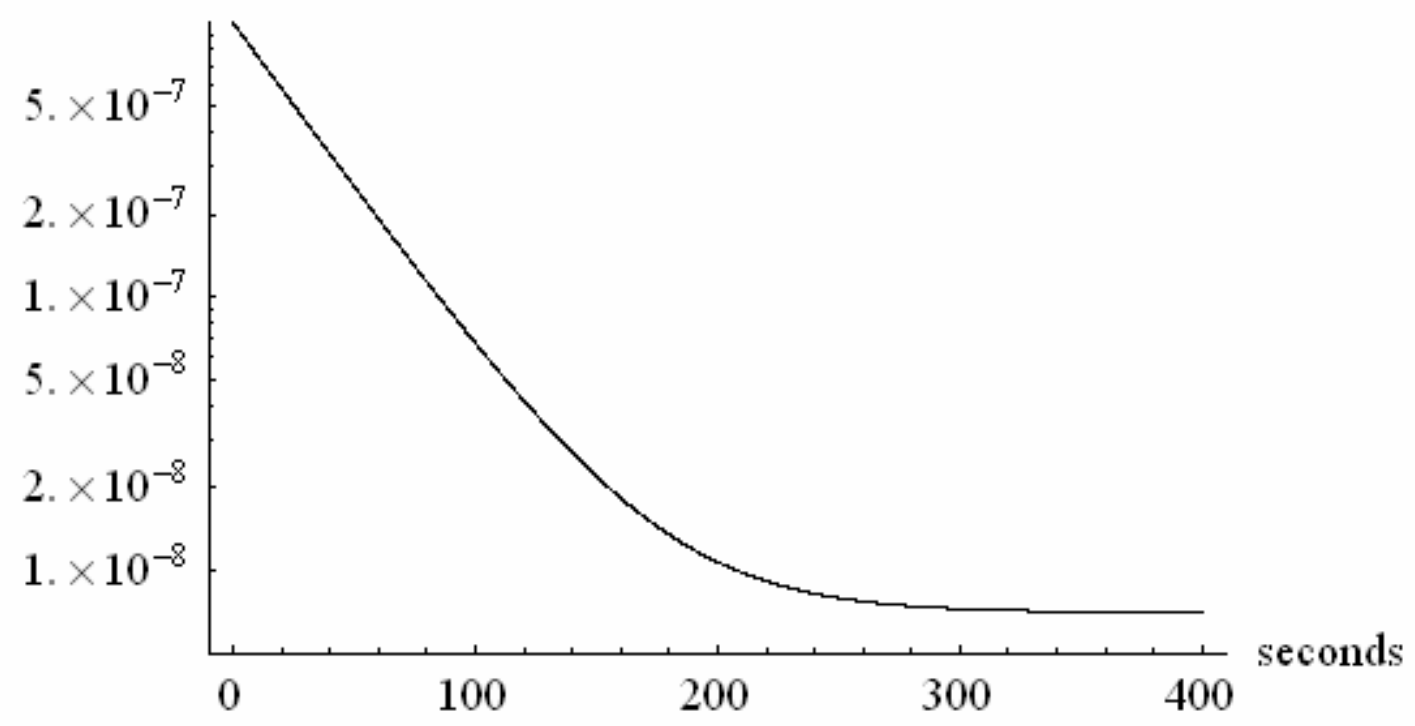

Fig. 5.4. Pressure history at the beam dump $(i=564)$. Final pressure $=7.0 \mathrm{x}$ $10^{-9}$ Torr.

\subsection{Pump failure analysis}

The consequences of the worse case pump failure was also calculated. Since the gun pressure has the least design margin (technically it does not meet the margin), the failures of pumps near the gun is the worse case. Results are summarized below. The failure of a pump at the P2 location $(z=47.45 \mathrm{~cm}, i=13)$ had less of an impact than the failure of pumps within the gun region. Thus the control systems designer should control the two gun pumps to minimize the likelihood of both failing at once.

\begin{tabular}{||l|c|c||}
\hline \multicolumn{1}{|c|}{ MODE } & GUN PRESSURE, TORR & $\begin{array}{c}\text { MARGIN } \\
\text { (DESIGN/CALCULATED) }\end{array}$ \\
\hline Normal & $3.33 \times 10^{-10}$ & 0.3 \\
\hline One gun pump failed & $5.0 \times 10^{-10}$ & 0.2 \\
\hline Both gun pumps failed & $5.0 \times 10^{-9}$ & 0.02 \\
\hline
\end{tabular}

Table 5.2. Worse case scenario: consequences of pump failure in the gun region 


\subsection{Time-dependent outgassing rate}

We also conducted a study of time-dependent effects of changing the outgassing rate. The outgassing rate is assumed to vary linearly with time starting at $1 \times 10^{-11}$ Torrlit $/ \mathrm{sec} / \mathrm{cm}^{2}$ and ending at $2 \times 10^{-12}$ Torr-lit $/ \mathrm{sec} / \mathrm{cm}^{2}$ after one day. Thus the outgassing rate used in the code is $q=-9.259 \times 10^{-17} t(\mathrm{sec})+1 \times 10^{-11}$ Torr-lit $/ \mathrm{sec} / \mathrm{cm}^{2}$.

The gun and beam dump locations were monitored to represent the extreme pressures in the system. Results are summarized in Table 5.3. Since the outgassing rate dropped by a factor of 5, the gun and beam dump pressures dropped by a factor of 5 . The time to reach these values is immaterial since the pressure will equilibrate in a time that matches the time for the outgassing rate to equilibrate. The time of one day was chosen for convenience.

\begin{tabular}{||c|c|c|c||}
\hline \hline & $\mathrm{t}=400 \mathrm{sec}$ & $\mathrm{t}=1$ day & $\begin{array}{c}\text { function ratio of } \\
400 \mathrm{sec} / 1 \text { day }\end{array}$ \\
\hline Gun pressure (Torr) & $1.61 \times 10^{-9}$ & $3.34 \times 10^{-10}$ & 4.83 \\
\hline SDMP pressure (Torr) & $3.49 \times 10^{-8}$ & $7.03 \times 10^{-9}$ & 4.96 \\
\hline $\begin{array}{c}\text { Outgassing rate (Torr- } \\
\text { lit/sec/ } / \mathrm{cm}^{2} \text { ) }\end{array}$ & $9.96 \times 10^{-12}$ & $2.00 \times 10^{-12}$ & 4.98 \\
\hline
\end{tabular}

Table 5.3. Worse case scenario: consequences of pump failure in the gun region

The histories of pressure in the gun and beam dump are shown in Figs. 5.5 and 5.6. Initially the pressure suddenly drops in the time needed to remove the volume of gas at $1 \times 10^{-6}$ Torr. This time is over $4 \mathrm{sec}$ in the gun and $300 \mathrm{sec}$ in the beam dump. Thereafter the pressure change is then just a function of the outgassing rate. The table below lists the pressures at $t=400 \mathrm{sec}$ and $t=1$ day to compare to the outgassing rates. The last figure shows the pressure profile at $t=1$ day (at $2 \times 10^{-12} \mathrm{Torr}-\mathrm{lit} / \mathrm{sec} / \mathrm{cm}^{2}$ ). The gun is at $i=3$ and SDMP is at $i=564$. 
Late Gun pressure, Torr

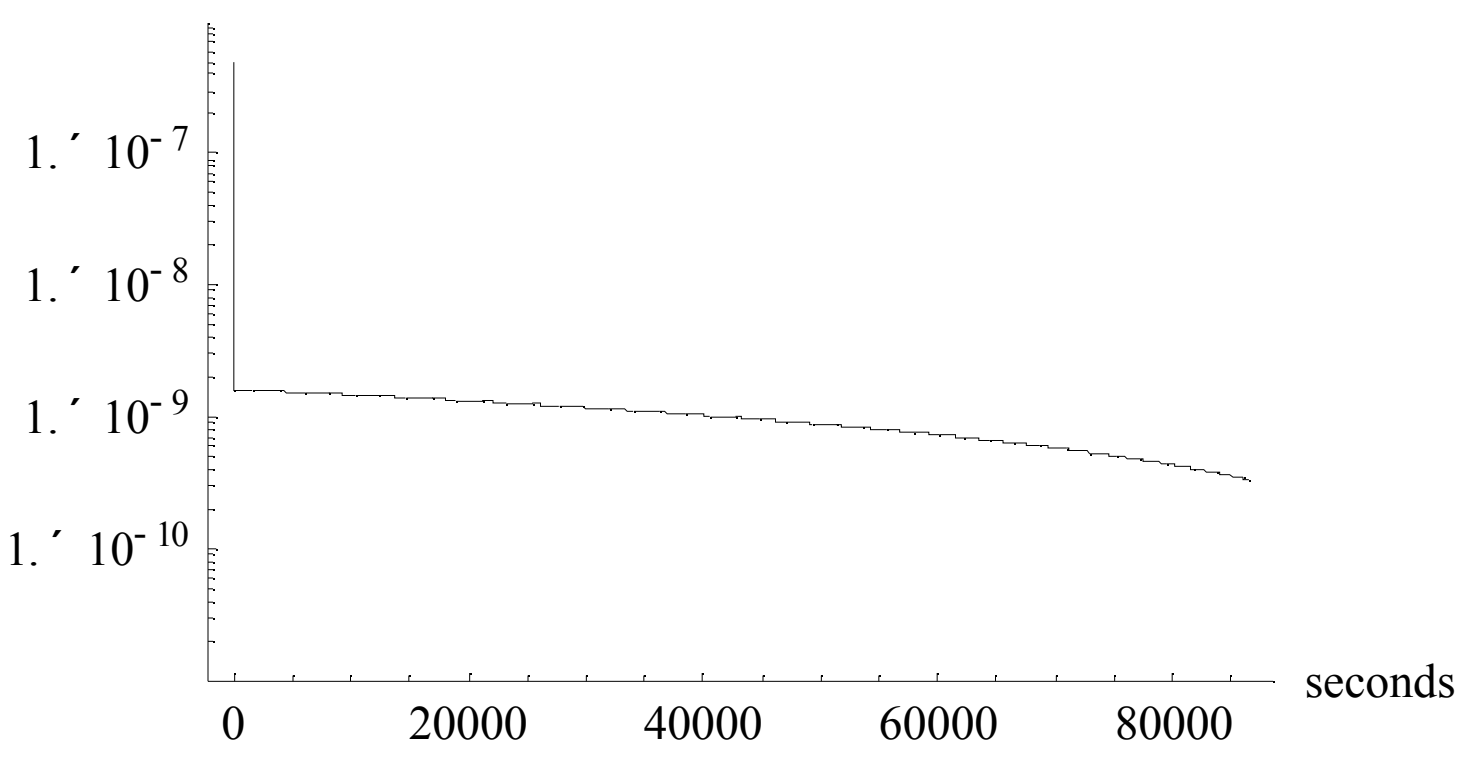

Fig. 5.5. Pressure history at the gun $(i=3)$.

Late SDMP pressure, Torr

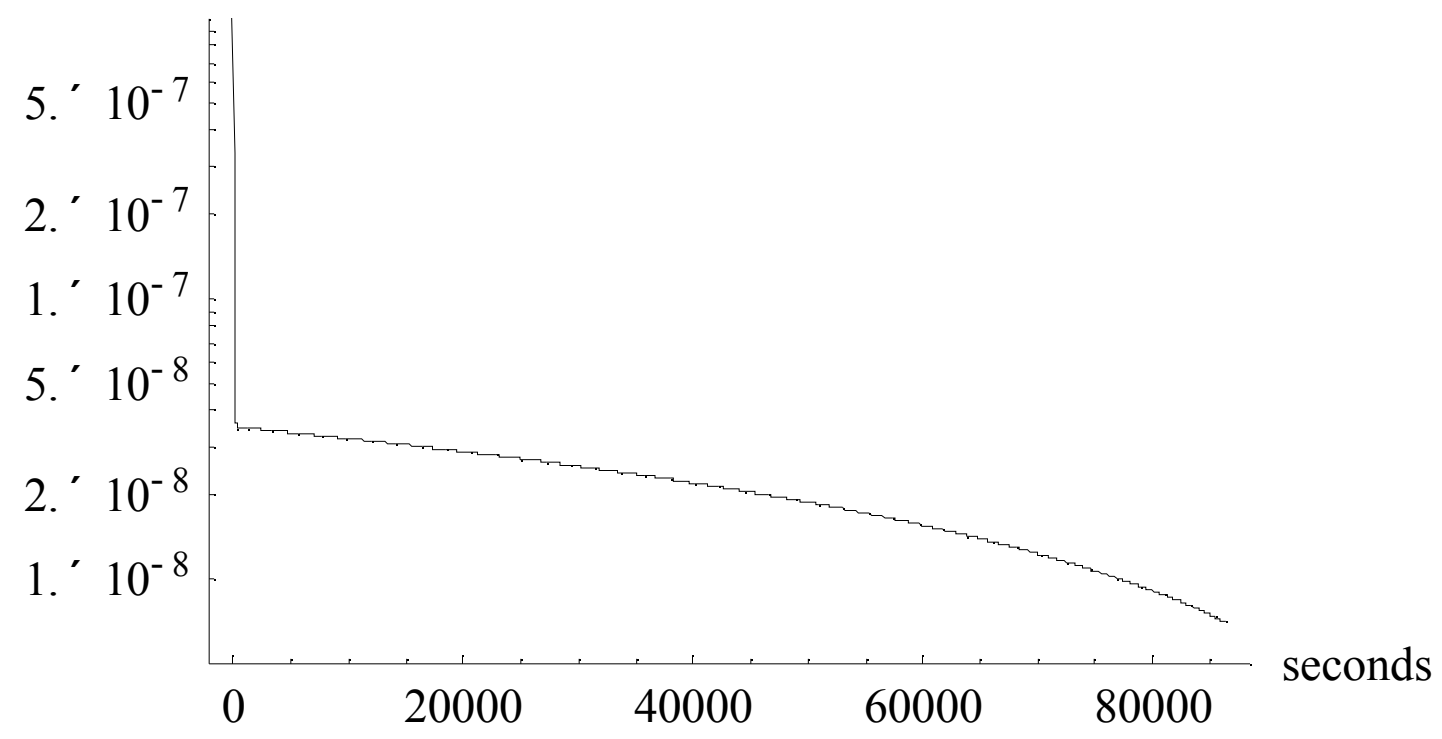

Fig. 5.6. Pressure history at the beam dump $(i=564)$. 


\section{$6 \quad$ Future work}

\subsection{Model improvements}

The code has the capability to model time-dependents effects. Thus the gauge locations could be included so that those pressures could be monitored. Then timedependent effects could be predicted such as pressure response at a gauge due to a failed pump or pressure spike at the gun due to a gauge turning on.

Additional nodes could be added right in front of the pumps. The present model lumps the node right in front of the pump with the node just after the connectors. Thus the actual pump speeds used in the gas load matrix is the effective pump speed. The final calculations will be unaffected but if one would like to compare gauge values with the pressure estimated from the ion currents then an adjustment needs to be made. However this pump pressure can be estimates just with the following formula. Since the actual pump speed is dependent on the throat pressure then using the throat pressure rather than the pressure just outside of the connector would provide a more accurate pump speed. This throat speed would be slightly less than what is presently used. According to Fig. 4.1, a lower throat pressure would result in a lower pump speed so that pressures overall would then increase. We can estimate this change with the following.

At steady state, the gas load balance is just $\Sigma \mathrm{Q}_{\mathrm{i} \text { in }}=\Sigma \mathrm{Q}_{\mathrm{i} \text { out }}$. With the present model, the connector volume and gas load $\mathrm{q}_{\mathrm{p}}$ is added into the nearest node at the tube. If this connector subvolume were treated as a separate node, then pump throat pressure $p_{p}$ would be a related to the pressure $\mathrm{p}_{\mathrm{i}}$ on the other side of the connector by

$$
\mathrm{p}_{\mathrm{p}}=\left(\mathrm{C}_{\mathrm{p}} \mathrm{p}_{\mathrm{i}}-\mathrm{q}_{\mathrm{p}}\right) /\left(\mathrm{S}_{\mathrm{p}}\left(\mathrm{p}_{\mathrm{p}}\right)+\mathrm{C}_{\mathrm{p}}\right)
$$

If we use the Varian Tee then $C_{p}=44$ lit $/ \mathrm{sec}$ and $\mathrm{q}_{\mathrm{p}}=213 \mathrm{~cm}^{2} \times 2.4 \times 10^{-12}=5.1 \mathrm{x}$ $10^{-10}$ Torr-lit/sec. Using Fig. xxx, a typical minimum pressure is $5 \times 10^{-10}$ Torr. Using Fig. 4.2, then the calculated pump speed is about $30.5 \mathrm{lit} / \mathrm{sec}$. With these numbers, then the throat pressure $p_{p}=2.8 \times 10^{-10}$ Torr which is a decrease of about $60 \%$ of those minima shown in Fig. $x x x$. Generally since the connector area is small then $p_{i} / p_{p}=S_{p}\left(p_{p}\right) /$ $\mathrm{C}_{\mathrm{p}}+1$.

This change in calculated throat pressure will change the calculated pumping speed. Referring again to Fig. 4.2, with the pump pressure lower by $60 \%$ then the calculated pump speed would drop from 30.5 to $29.2 \mathrm{lit} / \mathrm{sec}$. This speed drop would increase the overall pressure inversely by the same amount that would be $4 \%$. Thus the maximum pressure would increase from 3.3 to $3.4 \times 10^{-10}$ Torr. This change is in the noise for pressure monitoring. Generally though the smaller the connector conductance then the greater error in throat pressure and pump speed as compared to when the node just in front of the pump is eliminated and effective pump speed is used. 


\subsection{Suggested test}

The two rf windows in the $\mathrm{Y}$ in the gun section are assumed to outgas at $2 \times 10^{-12}$ Torr-li $/ \mathrm{sec} / \mathrm{cm}^{2}$. SLAC microwave staff have stated that, based on their past experience, the rf windows have had an insignificant contribution to the gas load in other linac systems due to the window's bakeout treatment prior to use. Similar but much larger alumina $\mathrm{rf}$ windows are in use at LANL. In designing the vacuum system, they assume that the rf window outgasses at $4.5 \times 10^{-9}$ Torr-lit $/ \mathrm{sec} / \mathrm{cm}^{2}$. This high outgassing rate was measured by ANL (3/1997) for LANL for the alumina rf windows running at $1 \mathrm{MW}$ on the APT/LEDA RFQ. If we use this high rate then the injector gun pressure would be $1 \mathrm{x}$ $10^{-8}$ Torr which would be damaging for the gun cathode. The large RFQ windows cannot be baked out in the same way as these gun windows so that the outgassing rates are much higher. However to be sure, I highly suggest that the outgassing rate of the gun windows under rf power are measured prior to installation. Then additional pumping in the gun region could be added if necessary to avoid poisoning the gun cathode. If $A$ Torrlit $/ \mathrm{sec} / \mathrm{cm}^{2}$ were the new outgassing rate, then roughly the required nominal pumping speed would be $A /\left(2 \times 10^{-12}\right.$ Torr-lit $\left./ \mathrm{sec} / \mathrm{cm}^{2}\right) \times 80 \mathrm{lit} / \mathrm{sec}$ to maintain the same gun pressure of $3 \times 10^{-10}$ Torr. 
Appendix I : IL and SASL component locations.

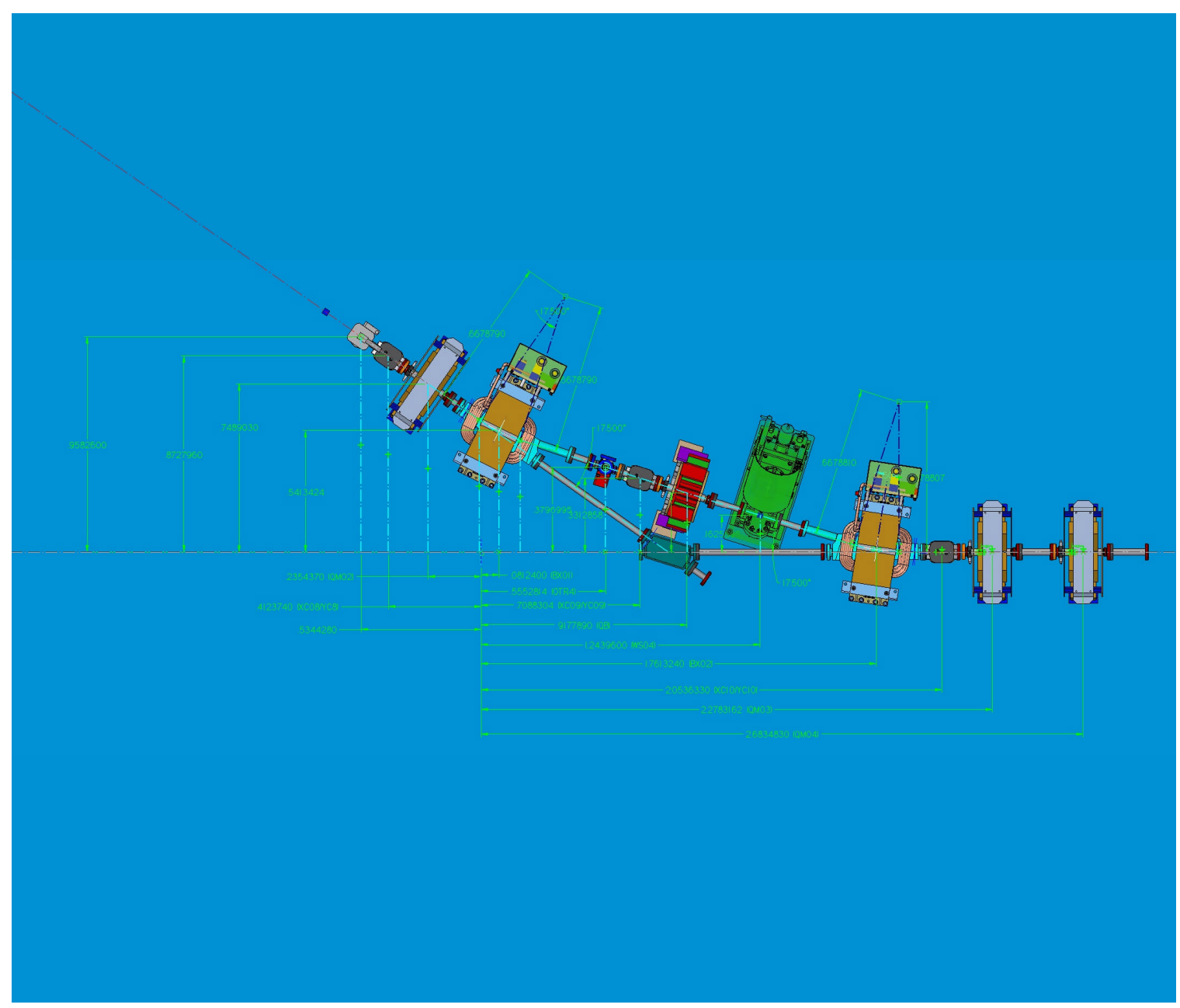

Fig. I.1. Drawing with $x-y$ locations used to determine the z-coordinates of components relative to the gun. (drawing entitled "INS PLAN.jpg) 


\section{Appendix II : Code to calculate $z$ values of components}

- input locations

(* In SAB PLAH2.jpg and IHS PLAH.jpg,

$x$ dimensions has some unknown

reference.

S dimensions are horizontally referenced to the split point just upstream of BX01 and $Y$ dimensions are referenced to the Linac -

convert all dimensions from meters to cm. Heed ( $x, y$, suml) locations of vvo4, injection line split (ILS), insertion line ion pump P8 (ILP8),

Linac merge point on insertion line at BX02, end of insertion line at $\mathrm{nM03}$, Linac merge point on Straight-Ahead spectrometer Line (SSL) (SLM), vo5 (same as WVI), bending magnet BXS on SSL (BXS), ion pump P9 on SSL (SLP9), beam dump (end of line) on SSL (SDMP). Locations along the insertion line are from the element chart (hard copy only). Locations along the spectrometer line are from the e-drawings SAB PLAN2.jpg chart $*$ )

( $*$ BEGIH IHPUT $*)$

W04SUIL $=16.54898603(* \mathrm{~m} *) ; \mathrm{Vv04x}=2031.465572(* \mathrm{~m} *) ; \mathrm{V} 04 \mathrm{Y}=0.95825884$

(* m *) ;

BX01deltaY $=1 / 4(.7489-.5413) ;($ guess from the jpg draving $\star$ );

BX01sunL $=17.29343203(* \mathrm{~m} *) ; \mathrm{BX01x}=2032.08124(* \mathrm{~m} *)$;

BX01s $=0.0812400 ;$

BX01y $=0.5413424(* \mathrm{~m} *)$;

WS04SUL $=18.51722803(* \mathrm{~m} *) ; \mathrm{WS04x}=2033.24396(* \mathrm{~m} *) ;$ WS04Y $=0.16255983$

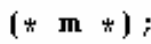

BX02SULL $=19.05702403(* \mathrm{~m} *) ; \operatorname{BX02x}=2033.761324(* \mathrm{~m} *)$;

$\operatorname{BS02y}=0.01161378(* \mathrm{~m} *)$;

ILP8SULL $=($ WS04SULL + BX02SUL $) / 2(* m *) ;$ ILP8x $=($ HS04x + BX02x $) / 2$

(* m *); ILP8y $=($ HSO4Y + BX02y) $/ 2(* \mathrm{~m} *)$;

(* P8 is midway between BX02 and wS04 *)

M03sul $=20.17437003(* \mathrm{~m} *) ; \operatorname{Mi03x}=2034.877683(* \mathrm{~m} *) ;$

m03y $=-.00000064(* \mathrm{~m} *)$;

(* SLM is midway between XCSI and VUSI (Vv05) *)

$\operatorname{xcsIs}=0.6484688(* \mathrm{~m} *) ; \operatorname{xcs} I_{Y}=0.1299858(* \mathrm{~m} *)$;

WUSIs $=1.0161935(* \mathrm{~m} *) ;$ VVSIY $=-0.1274977(* \mathrm{~m} *)$;

SLMs $=(X \operatorname{CSI}+$ VUSIs $) / 2(* \mathrm{~m} *) ; \operatorname{SLMY}=0(* \mathrm{~m} *)$;

BXSs $=1.7289390(* \mathrm{~m} *)$; BXSY $=-0.5582677(* \mathrm{~m} *)$;

(* ion pump 9 is half-way between 0S02 and MSI *)

$\operatorname{SLP} 9 s=(3.0313740+3.4837740) / 2(* \mathrm{~m} *) ; \operatorname{SLP} 9 \mathrm{Y}=-0.6165247(* \mathrm{~m} *) ;$

SDMPs $=4.3730200(* \mathrm{~m} *) ; \operatorname{SDMPY}=-0.6165247(* \mathrm{~m} *)$;

(* find distance from v04 to IL-SL split *) 


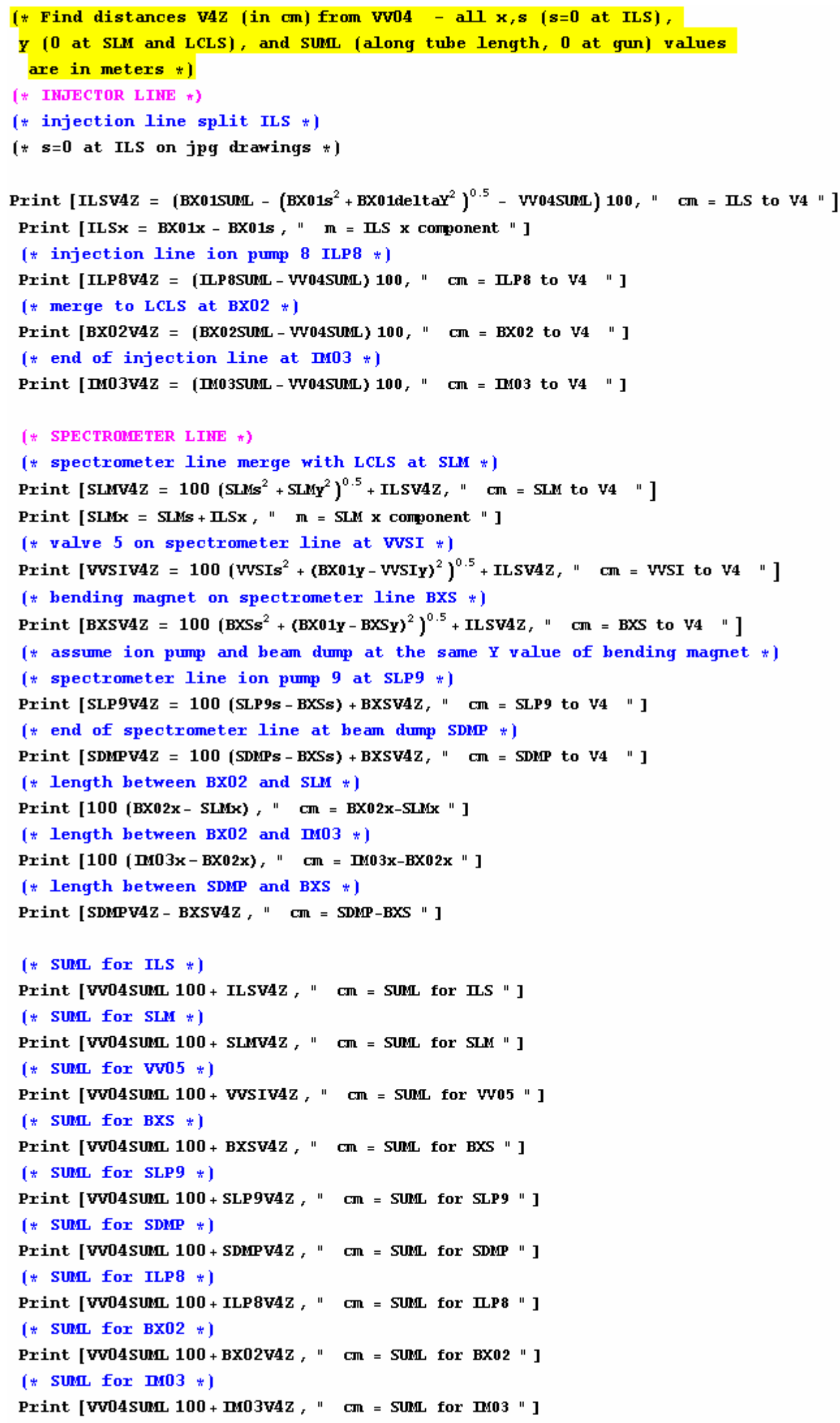




$$
\begin{aligned}
& 64.8043 \mathrm{~cm}=\text { ILS to } \mathrm{V} 4 \\
& \text { 2032. II }=\text { ILS } \times \text { component } \\
& 223.814 \mathrm{~cm}=\text { ILP8 to } \mathrm{V} 4 \\
& 250.804 \text { CII }=\text { BX02 to } \mathrm{V} 4 \\
& 362.538 \mathrm{CIn}=\mathrm{IMO} 3 \text { to } \mathrm{V} 4 \\
& 148.037 \text { Cm }=\text { SLM to } \mathrm{V} 4 \\
& \text { 2032.83 Ii }=\text { SLM } x \text { component } \\
& 186.459 \mathrm{~cm}=\text { WSI to } \mathrm{V} 4 \\
& 269.704 \text { cm }=\text { BXs to } \mathrm{V} 4 \\
& 422.567 \text { CII }=\text { SLP9 to } \mathrm{V} 4 \\
& 534.112 \text { CII }=\text { SDMP to } \mathrm{V} 4 \\
& 92.8993 \mathrm{Cm}=\mathrm{BX02 \textrm {X }}-\mathrm{SLMx} \\
& 111.636 \text { CII }=\text { IM03X }-\mathrm{BX} 02 \mathrm{x} \\
& \text { 264.408 CII }=\text { SDMP-BXS } \\
& 1719.7 \text { cm }=\text { SUNL for ILS } \\
& 1802.94 \text { cm }=\text { SUNL for SLM } \\
& 1841.36 \mathrm{~cm}=\text { SUML for } \mathrm{W} 05 \\
& 1924.6 \mathrm{~cm}=\text { STNML for BXS } \\
& 2077.47 \mathrm{~cm}=\text { SUML for SLP9 } \\
& 2189.01 \mathrm{~cm}=\text { SUNL for SDMP } \\
& 1878.71 \mathrm{~cm}=\text { STML for ILP8 } \\
& 1905.7 \text { Cm }=\text { SUNL for BX02 } \\
& 2017.44 \mathrm{~cm}=\text { SUML for IMO3 }
\end{aligned}
$$

